\title{
Optimasi Meta Tag dan Mobile Friendly Dalam Meningkatkan Search Engine Optimization Pada Website E-Brosur
}

\author{
Wahyu Sindu Prasetya \\ STMIK Pontianak; Jl. Merdeka Barat No. 372, (0561) 735555 \\ e-mail: E-mail: wahyusindu@stmikpontianak.ac.id
}

\begin{abstract}
Abstrak
Kondisi saat ini sangat penting untuk memaksimalkan agar konten yang terkandung dalam website e-brosur dapat dengan mudah ditemukan dan dapat dibaca dengan baik oleh pengguna yang menggunakan perangkat mobile. Search engine memiliki algoritma yang terus berubah dari waktu ke waktu sehingga menjadi tantangan bagi pengembang sistem untuk menghadirkan website yang kontennya bisa dikenal oleh search engine dan bahkan dapat muncul diposisi paling atas. Penelitian ini bertujuan untuk menghasilkan SEO pada website ebrosur dengan cara mengoptimalkan penggunaan meta tag dan mobile friendly. Website ebrosur dikembang dengan pendekatan user experience (UX) dalam merancang user interface (UI) mengingat keterbatasan layar dalam menampilkan informasi dan kemudahan dalam melakukan navigasi. Hasil penelitian telah mengoptimalkan meta tag dan mobile friendly pada webite e-brosur sehingga dapat memberikan peluang yang cukup besar terhadap peringkat pada search engine google. Keterbatasan penelitian ini terletak pada alat pengujian yang meta tag maupun pengujian mobile friendly sehingga belum bisa dikatakan bahwa website e-brosur akan pasti berada diposisi paling atas ketika pencarian menggunakan google. Masih perlu dikembangkan dengan menggunakan algoritma search engine google terupdate.
\end{abstract}

Kata kunci-3-5 Mobile Friendly, meta tag, SEO, UX

\begin{abstract}
Current conditions are very important to maximize the content contained in the e-brochure website can be easily found and can be read properly by users who use mobile devices. Search engines have algorithms that change from time to time, making it a challenge for system developers to present websites whose content can be recognized by search engines and can even appear at the top. This study aims to produce SEO on the e-brochure website by optimizing the use of meta tags and mobile friendly. The e-brochure website was developed with a user experience (UX) approach in designing a user interface (UI) given the limitations of the screen in displaying information and the ease of navigation. The results of this study have optimized the meta tag and mobile friendly on the e-brochure website so that it can provide a large enough opportunity to rank on the google search engine. The limitation of this research lies in the meta tagging and mobile friendly testing tools so it cannot be said that the e-brochure website will definitely be in the top position when searching using Google. Still needs to be developed using the updated google search engine algorithm.
\end{abstract}

Keywords-3-5 Mobile Friendly, meta tag, SEO, UX

\section{PENDAHULUAN}

Melakukan optimasi website memang sangatlah penting agar website tersebut bisa berfungsi dengan lebih baik [1]. Dalam pencapaian optimasi website dapat dilakukan dengan 
cara menerapkan teknik mobile friendly dan Search Engine Optimization (SEO) [2]. Membuat website yang memiliki tampilan mobile friendly bisa menghasilkan website yang optimal, baik dari sisi loading time maupun maupun sifat responsifnya. Website yang responsif merupakan website yang mampu merespons secara optimal ketika user mengakses suatu halaman web melalui perangkat mobile [3]. Dengan kata lain, apa pun jenis perangkat yang dipakai untuk mengakses website, tampilan dan fungsinya tetap normal dan bekerja sebagaimana mestinya. Ada tiga alasan utama menghadirkan mobile friendly pada sebuah website yaitu (1) traffic jumlah pengguna ponsel meroket tiap tahunnya' (2) mobile first index; (3) dan mobile search Engine Optimization (SEO). Berdasarkan data dari laman databoks, lebih dari setengah populasi di Indonesia atau 56,2\% telah menggunakan ponsel pintar pada 2018. Pada akhir tahun 2019 mencapai 92 juta unit smartphone atau sekitar $63,3 \%$ penduduk Indonesia menggunakan smartphone. Bahkan diprediksi hingga tahun 2025 terdapat 89,2\% penduduk Indonesia menggunakan smartphone. Sejak kemunculan smartphone di era komunikasi yang terus berkembang ini, sebagian besar orang lebih sering mengakses internet melalui perangkat mobile. Pertumbuhan pengguna smartphone yang terus meningkat tentunya harus menjadi cerminan bagi pengembang sistem untuk memperhatikan pada sisi mobile friendly. Website yang mobile friendly akan lebih diprioritaskan oleh Google dalam proses indexing website [4]. Dari hasil indeks ini pulalah, google menentukan ranking pencarian sebuah website[5].

Sebagai upaya memberikan hasil pencarian yang lebih baik kepada pengguna mesin pencari yang menggunakan smartphone, pada tahun 2018 Google resmi merilis algoritma terbarunya yaitu, Google Mobile First Index (MFI). Kebijakan mobile first index muncul karena jumlah penggunaan mobile lebih tinggi dari pada penggunaan dekstop dalam berselancar di internet. Google mobile first index telah menjadi salah satu penilaian Google dalam menentukan rangking sebuah website yang menggunakan versi mobile [6]. Sebelum hadirnya teknologi mobile, Google hanya melihat performa website melalui versi desktop, namun semenjak 2018, Google juga menilai performa website pada versi mobile dalam merangking website. Oleh karena itu, jika website memiliki performa yang buruk saat diakses menggunakan perangkat mobile, maka akan mendapat rangking yang buruk juga di mesin pencarian google. Faktor lain yang juga tidak kalah pentingnya adalah sistem peringkat website google yang telah diperbarui untuk menampilkan hasil pencarian yang lebih baik bagi pengguna smartphone. Website yang tidak dioptimasi dengan baik, maka keberadaannya akan dihilangkan dari hasil pencarian google untuk perangkat mobile atau akan berada di urutan bawah mesin pencari. Secara garis besar faktor utama penentu website sudah optimal di versi mobile adalah dengan adanya meta viewport dan pagespeed versi seluler yang baik [7]. Tag meta viewport adalah cara mudah untuk mengontrol bagaimana situs web muncul di seluler. Tag meta viewport memberi tahu browser agar menyesuaikan lebar halaman dengan perangkat layar digunakan.

Optimasi website juga dapat dicapai dengan cara melakukan optimasi SEO [8]. SEO telah menjadi salah satu kunci utama keberhasilan optimasi sebuah website. Optimasi meta tag merupakan strategi SEO yang secara signifikan membantu menampilkan website pada posisi teratas sehingga trafik web pengunjung meningkat [9]. Meta tag akan memberitahu mesin pencari (google) mengenai konten yang ada pada website [10]. Meta tag dalam HTML terdiri dari tiga jenis, yakni meta title, meta description, dan meta keyword [11]. Meta title adalah judul halaman website yang muncul di hasil pencarian Google [12]. Meta tag menjadi hal yang pertama kali dilihat oleh pengunjung website pada hasil pencarian, sehingga pengembang harus mampu membuat meta title yang unik dan menarik. Meta description adalah tag HTML yang berisi penjelasan singkat mengenai isi halaman website [13]. Meta title description akan muncul di bagian bawah meta title. Meta keyword adalah informasi keyword atau kata kunci yang digunakan oleh sebuah website [14]. Meta keyword akan memberitahu mesin pencari mengenai isi postingan atau artikel pada website. Penelitian ini bertujuan untuk meningkatkan trafik pengunjung website e-brosur STMIK Pontianak dengan menerapkan teknik-teknik SEO. 


\section{METODE PENELITIAN}

Penelitian ini menggunakan metode user experience (UX) research. Menurut Interaction Design, user experience (UX) research adalah penelitian menyeluruh dari pengguna atau user dan kebutuhannya. Hal ini dilakukan untuk memberikan masukan pada proses desain user experience [15]. Proses riset ini bertujuan untuk mengidentifikasi, menemukan kebutuhan, dan kesulitan dari para pengguna. Tujuan dilakukannya penelitian tersebut tentunya untuk meningkatkan kualitas dan membuat desain produk agar bisa menjadi lebih baik dan sesuai dengan keinginan dari para target pengguna. Metode perancangan sistem menggunakan UserCentered Design (UCD). Pendekatan UCD adalah perancangan sebuah desain interface yang memusatkan pengguna sebagai peran utama dalam menentukan kebutuhan sistem. Konsep dari UCD adalah pengguna sebagai pusat dari proses pengembangan sistem [16]. Pendekatan UserCentered Design (UCD) melibatkan pengguna sejak tahap analisa, desain, testing, build/redesign [17]. Hal ini penting mengingat kemudahan dalam menggunakan sistem dan ketersediaan fitur yang sesuai akan menjadi daya tarik untuk terus menggunakan sistem. Terdapat 4 (empat) tahap dalam pendekatan UCD yaitu understand context of use, specify user requirements, design solutions and evaluation against requirements [18].

\section{HASIL DAN PEMBAHASAN}

\section{Understand context of use}

Website e-brosur merupakan sebuah website yang dapat dipergunakan untuk menggantikan brosur versi cetakan. Melalui e-brosur, pengguna dapat mengakses berbagai informasi yang terkandung didalam brosur layaknya sebuah brosur versi cetakan. Melalui ebrosur, pengguna dapat mengakses informasi profil perguruan tinggi, visi dan misi perguruan tinggi, jenjang dan program studi, matakuliah keahlian, jadwal kuliah, penerimaan dan pendaftaran, fasilitas, kegiatan mahasiswa dan pendaftaran ulang. Melalui informasi ini, diharapkan pengguna dapat memahami dengan jelas apa yang dimiliki oleh perguruan tinggi. Ketersediaan konteks menjadi fokus utama pada sistem e-brosur. Kemudahan dalam mengakses informasi juga menjadi pokok perhatian dalam pengembangan sistem. Untuk rancangan SEO On Page akan diterapkan optimasi terhadap komponen-komponen

\section{Specify user requirements}

Memahami kebutuhan pengguna menjadi periotas yang harus dihasilkan dan untuk mendapatkan kebutuhan pengguna, diperlukan teknik brainstorming yaitu mengembangkan solusi kreatif dalam menghadapi sebuah permasalahan. Brainstorming mencoba melakukan analisis kebutuhan pengguna dan mendapatkan hasil seperti rancangan tampilan antarmuka yang menarik, mudah dipergunakan, dan menganalisis fitur aplikasi yang dapat dipergunakan oleh pengguna, baik itu hanya sekedar mengakses informasi maupun melakukan pendaftaran online. Berikut ini adalah fitur-fitur yang akan dikembangkan pada website e-brosur:

Tabel 1. Daftar Fitur

\begin{tabular}{|l|l|}
\hline Nama Fitur Aplkasi & Keterangan Fitur \\
\hline Profil & $\begin{array}{l}\text { Menampilkan informasi seputar asal mula perguruan tinggi, akresitasi } \\
\text { institusi dan program studi, kompetensi lulusan, pembelajaran berbasis e- } \\
\text { learning, sertifikasi kompetensi dan program beasiswa. }\end{array}$ \\
\hline Visi dan Misi & Menjelaskan visi dan misi STMIK Pontianak \\
\hline $\begin{array}{l}\text { Jenjang dan Program } \\
\text { Studi }\end{array}$ & $\begin{array}{l}\text { Menyediakan informasi jenjang pendidikan, program studi yang ditawarkan } \\
\text { dan tujuan program studi. }\end{array}$ \\
\hline $\begin{array}{l}\text { Mata Kuliah Keahlian } \\
\text { Sistem Informasi }\end{array}$ & $\begin{array}{l}\text { Menjelaskan Mata Kuliah Keahlian Program Studi Sistem Informasi, pilihan } \\
\text { bidang minat, dan mata kuliah pilihan bidang lain }\end{array}$ \\
\hline $\begin{array}{l}\text { Mata Kuliah Keahlian } \\
\text { Teknik Informatika }\end{array}$ & $\begin{array}{l}\text { Menjelaskan Mata Kuliah Keahlian Program Studi Teknik Informatika, } \\
\text { pilihan bidang minat, dan mata kuliah pilihan bidang lain }\end{array}$ \\
\hline
\end{tabular}




\begin{tabular}{|l|l|}
\hline Nama Fitur Aplkasi & Keterangan Fitur \\
\hline Jadwal Kuliah & Memberikan informasi jadwal kuliah berupa kelas pagi dan kelas sore \\
\hline $\begin{array}{l}\text { Penerimaan dan } \\
\text { Pendaftaran }\end{array}$ & $\begin{array}{l}\text { Memberikan informasi syarat penerimaan dan waktu pendaftaran, dimana } \\
\text { waktu pendaftaran dibagi kedalam dua gelombang. }\end{array}$ \\
\hline Pendaftaran Ulang & $\begin{array}{l}\text { Memberikan informasi syarat pendaftaran dan pendaftaran ulang bagi } \\
\text { mahasiswa yang diterima. }\end{array}$ \\
\hline Video & Menampilkan profil, kegiatan wisuda dan kegiatan pratikum robot. \\
\hline Pendaftaran Online & $\begin{array}{l}\text { Memberikan formulir untuk mendaftara secara online bagi calon mahasiswa } \\
\text { yang berminat }\end{array}$ \\
\hline
\end{tabular}

\section{Design solutions}

Merancang solusi dari user requirements yang telah dijelaskan pada proses sebelumnya, proses perancangan ini akan melewati beberapa tahapan mulai dari rancangan arsitektur aplikasi, rancangan diagram dan rancangan antarmuka aplikasi. Desain arsitektur yang ideal harus dapat memenuhi kebutuhan pengguna, compatible/ independent secara teknologi, dapat digunakan kapan saja secara mudah dan handal, mudah dikembangkan dan dapat diakses sebanyak mungkin oleh pengguna. Tahapan ini menghasilkan model rancangan yang lebih konkrit dari suatu sistem e-brosur. Penelitian ini lebih cenderung kepada bagaimana melakukan optimasi terhadap meta tag dan mobile friendy. Oleh karenanya pada tahapan ini akan dijelaskan secara bertahap kegiatan optimasi untuk meningkatkan SEO pada website e-brosur.

\section{a. Optimasi Meta Tag}

Adanya update secara terus-menerus pada algoritma sebuah search engine, maka pengembang sistem juga dituntut untuk mengikuti pola SEO sesuai dengan algoritma terbaru tersebut, hal ini bertujuan agar website tetap dinilai baik oleh search engine, sehingga mendapatkan peringkat yang diharapkan. Tag Meta umumnya ditempatkan pada bagian $<$ head $>$ $<$ /head $>$ dari HTML dan terdiri dari beberapa atribut yang diantaranya yaitu charset, http-equiv dan name.

1) Meta Tag Title

Tag Title ini sebenarnya memang bukanlah sebuah syntax Tag Meta, namun dalam optimasi SEO Tag Title ini sangatlah penting. Title dioptimalisasikan dengan keyword, dimana keyword akan disisipkan pada character pertama pada title agar tidak terpotong oleh mesin pencari. Judul tidak boleh terlalu pendek atau terlalu panjang karena google biasanya menampilkan 50-60 karakter pertama pada judul halaman web. Google memiliki algoritma untuk melakukan pencarian terhadap persamaan kata, namun akan lebih jika quey sesuai dengan judul halaman web.

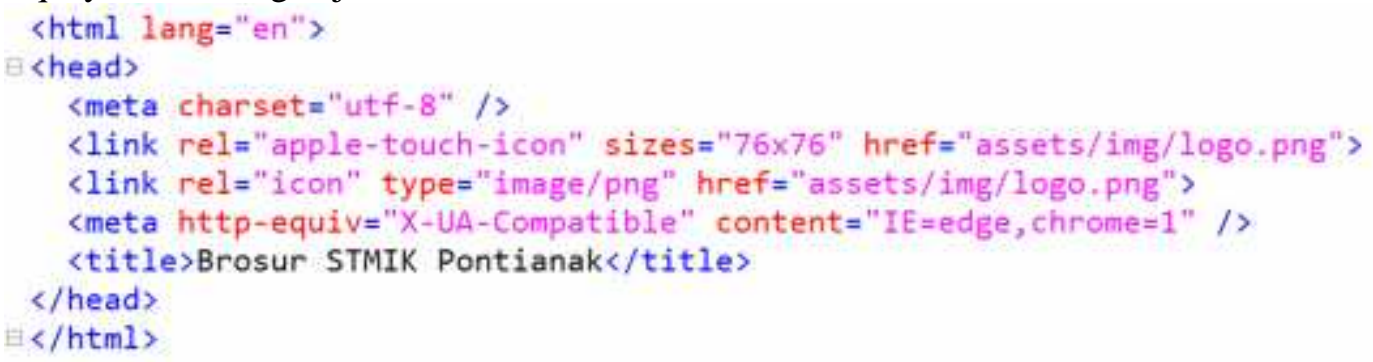

2) Deskripsi Meta (Meta Description)

Tag Meta Description berfungsi untuk mendeskripsikan sebuah kesimpulan dari isi halaman website e-brosur. Dalam praktiknya, deskripsi meta merupakan satu paragraf singkat yang akan digunakan oleh Google (atau mesin pencari lain) untuk ditampilkan pada hasil pencarian. Hal yang paling penting adalah memastikan tidak ada konten deskripsi meta yang duplikat. Membuat deskripsi meta ditujukan untuk meningkatkan klik pengguna sehingga dianggap perlu menuliskan sesuatu yang menarik perhatian namun masih tetap relevan. Panjang ideal deskripsinya adalah 150-160 karakter dan tidak lebih dari 960 pixels 
agar deskripsinya tidak terpotong. Untuk melakukan pengecekan panjang deskripsi yang ideal, penelitian ini menggunakan Google SERP Simulator. Berikut ini tampilan dari Google SERP Simulator:

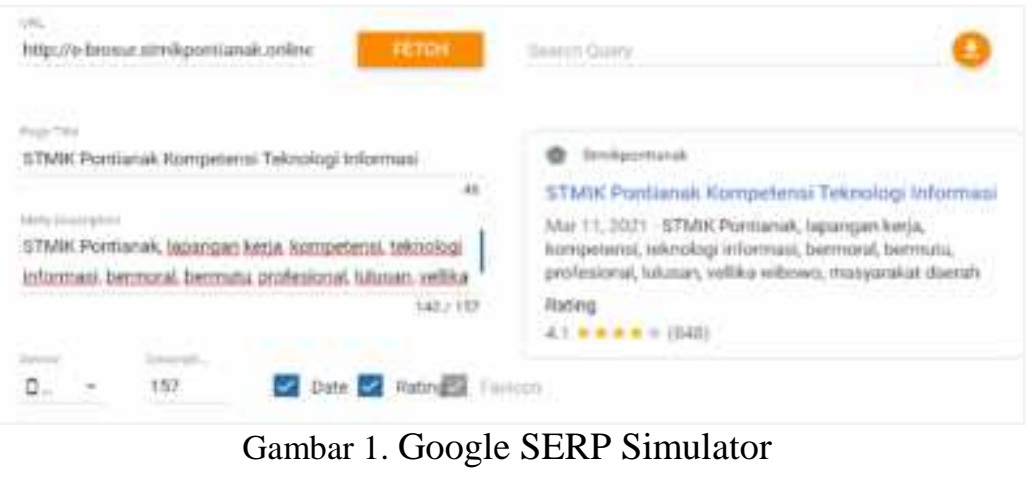

Dari gambar tersebut dapat dijelaskan bahwa jumlah karakter tidak melebihi dari apa yang sudah ditetapkan yakti 157 karakter. Berikut ini adalah tag meta description dari website ebrosur:

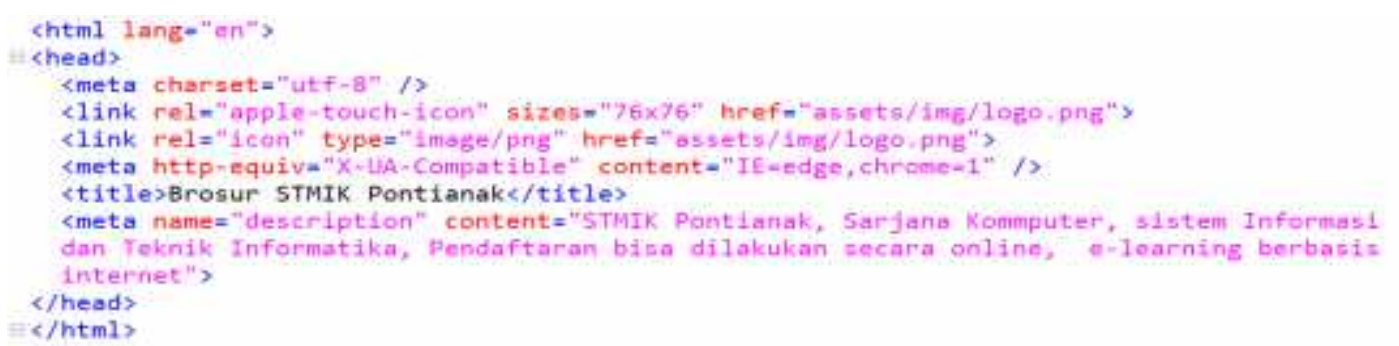

3) Kata Kunci Meta (Meta Keywords)

Untuk menemukan kata kunci yang tepat, penelitian ini menggunakan tools KWFinder yang merupakan salah satu sebuah software atau aplikasi berbasis web untuk melakukan riset keyword. KWFinder adalah tool yang memiliki display halaman lebih tepat dan banyak memberikan informasi yang akan memudahkan pengguna dalam memanfaatkan platform tersebut. Berikut ini adalah meta keywords yang ada di website e-brosur:

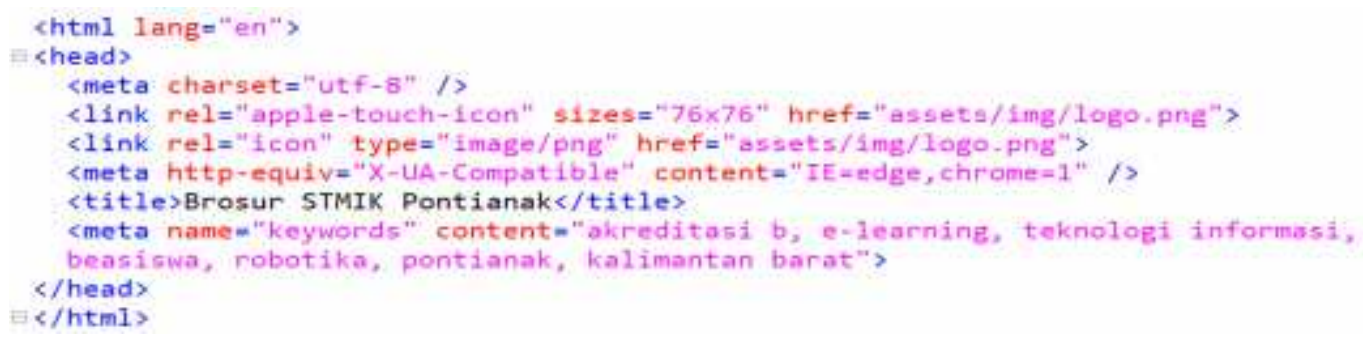

b. Website Mobile-Friendly

Algoritma Google Mobile First Index hadir untuk memenuhi kebutuhan pengguna yang kini lebih banyak menggunakan perangkat mobile untuk mengakses internet. Pemilik website pun dituntut untuk menyediakan website yang mobile-friendly sehingga bisa memberikan user experience yang baik kepada pengunjung website. Dengan begitu semua pihak diuntungkan. Jika website versi mobile performanya yang buruk, kemungkinan besar akan berpengaruh buruk pada kualitas SEO website keseluruhan. Desain web yang ramah seluler dimaksudkan untuk memberikan pengalaman pengguna yang lebih baik. Desain ramah seluler mencakup font yang dapat dibaca dengan jelas, gambar dan video yang memenuhi seluruh layar, serta bentuk dan tombol yang besar dan terlihat jelas. Menu selalu melekat di layar, jadi menavigasi ke halaman mana pun sangat mudah dalam desain yang ramah seluler. Sebagai hasil dari desain ini, pengunjung cenderung bertahan di situs web 
untuk waktu yang lama, yang pada akhirnya meningkatkan skor kegunaannya. Inilah sebabnya mengapa desain web yang ramah seluler menghasilkan peningkatan peringkat mesin pencari. Berikut ini adalah cara dalam menghasilkan website e-brosur yang mobile friendly:

1) Gunakan Desain Responsif

Desain responsif memungkinkan web developer membuat website yang akan mudah dilihat dari beragam ukuran di perangkat yang berbeda. Hal ini akan mengurangi tugas yang harus dilakukan web developer ketika menciptakan sebuah website. Ketika desain responsif digunakan pada sebuah website, maka halaman website dapat mendeteksi ukuran layar, orientasi pengguna dan mengubah tata letak yang sesuai. Dengan menggunakan relative units, tampilan akan dapat mudah menyesuaikan dengan keadaan layar. Pada CSS dibawah, ketika lebar layar berukuran 960px atau kurang dari itu, maka jalankan script, atur lebar sesuai script. Disini lebar wrapper diatur menjadi 96\% saja dari lebar layarnya. Sedangkan konten diatur agar lebarnya 66\% saja dari lebar layar, dan sidebar lebarnya menjadi $30 \%$.

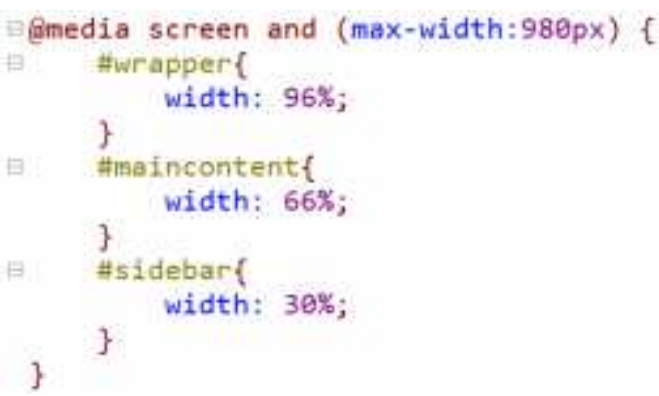

Pada CSS dibawah, jika ukuran layar hanya 680px atau kurang, maka jalankan script lain seperti dibawah ini, dimana lebar/width diatur menjadi auto, atau otomatis mengikuti lebar layarnya, begitu juga dengan sidebar, dibuat auto juga agar lebarnya mengikuti lebar layar, sedangkan float nya diatur none agar div elemennya tersusun kebawah.

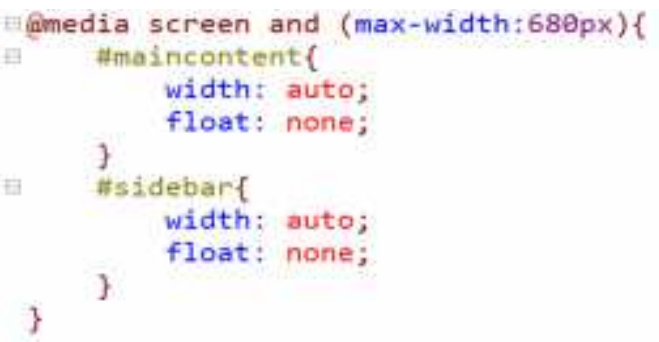

Selanjutnya pada CSS dibawah ini, jika ukuran layar 480px atau kurang dari itu (biasanya ini ukuran untuk ponsel/smartphone), maka bisa disembunyikan sidebar dan atur agar tinggi header menjadi auto. Semua kondisi bisa tentukan sendiri berdasarkan kebutuhan.

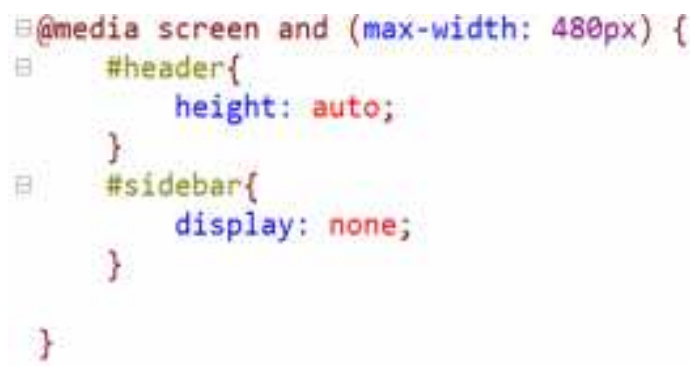

2) Selalu Sertakan Viewport Meta Tag

Viewport adalah daerah virtual yang digunakan oleh mesin rendering browser untuk menentukan bagaimana konten diskala dan diukur. Karena itulah viewport adalah sebuah kode kritis ketika membangun website mobile-friendly. Tanpanya, website tidak akan 
berfungsi dengan baik pada perangkat mobile. Viewport meta tag memberitahukan ke browser berupa halaman wesbite yang sesuai dengan ukuran layar. Berikut viewport pada website e-brosur:

smeta content=' width=device-width, initial-scale=1. $\theta$, maximum-scale=1.e, user-scalable- $\theta$, shrink-to-fit-no' name-'viewport' />

Tag meta viewport akan memberikan intruksi ke browser untuk mengatur dimensi dan sekala web. Nilai width=device-width, artinya lebar web akan mengikuti lebar dari layar perangkat yang digunakan. Nilai inital-scale $=1$, artinya web akan diberikan skala (zoom) menjadi 1 (normal). Bagian initial-scale $=1.0$ menyetel tingkat zoom awal saat halaman pertama kali dimuat oleh browser.

3) Gunakan Video YouTube di Website E-Brosur

Jika menggunakan banyak elemen video, maka cara video terlihat dalam tampilan di perangkat mobile akan berbeda dan sulit untuk disaksikan. Karena itu, menggunakan video YouTube adalah solusi untuk mengatasi kesulitan dalam menyaksikan video melalui perangkat mobile. Untuk itu, hanya perlu menambahkan kode CSS dengan menambahkan kelas agar frame video dari Youtube bisa menyesuaikan ukuran kontainer halaman web.

Berikut ini CSS untuk class video-container:

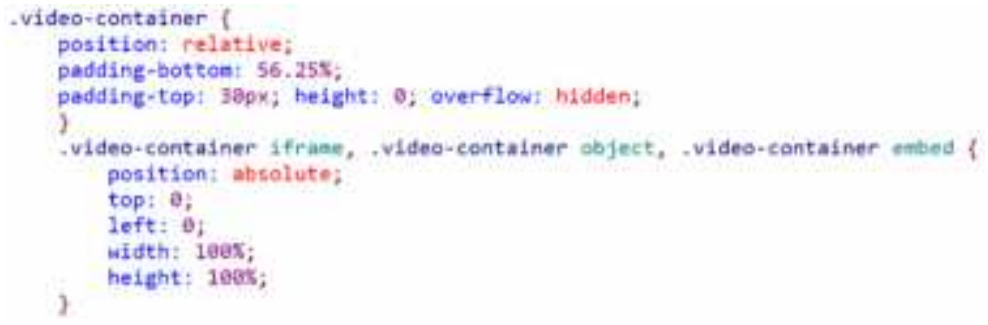

Kode embed Youtube setelah ditambahkan class video-container:

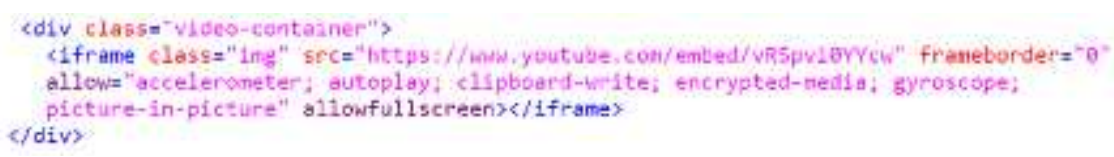

Berikut ini adalah tampilan video yang dijalankan pada perangkat mobile (Samsung Galaxy S7):

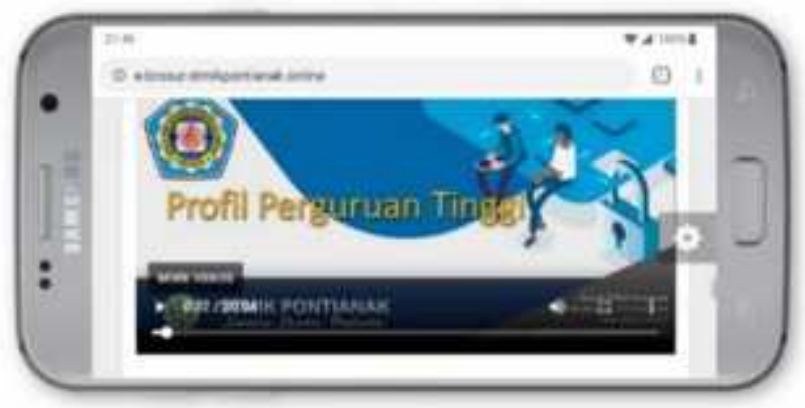

Gambar 2. Video YouTube Profil

4) Optimizing Responsive Design for Mobile Search

Situs yang dioptimalkan untuk seluler adalah situs web yang jauh lebih canggih. Dioptimalkan untuk seluler berarti situs tersebut akan memformat ulang dirinya sendiri. Tombol navigasi yang lebih besar, konten yang diformat ulang, dan gambar yang dioptimalkan secara berbeda muncul saat pengguna menggunakan mobile atau perangkat lain. Berikut ini adalah tampilan website e-brosur yang responsif: 


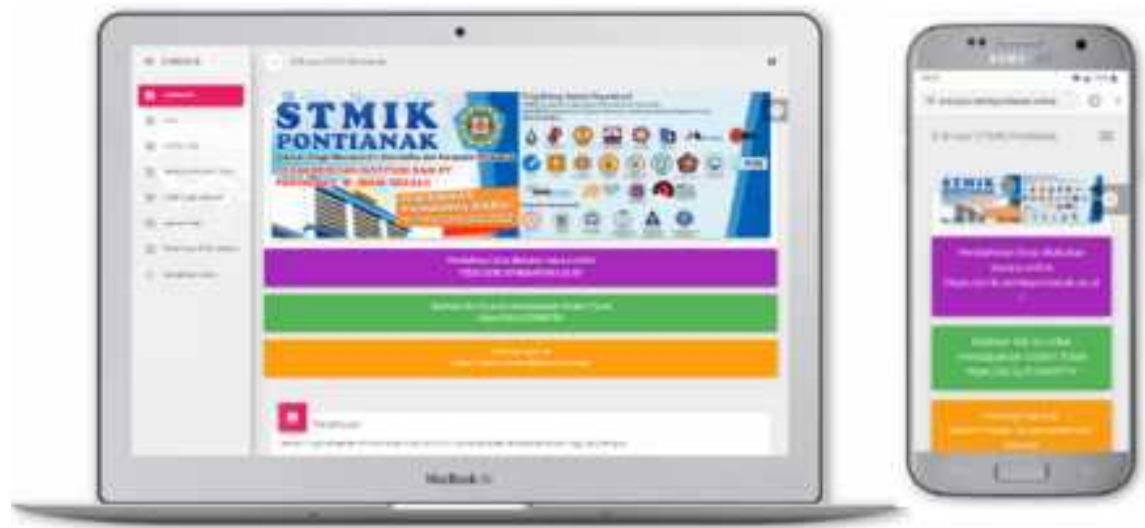

Gambar 3. Tampilan Website E-Brosur Responsif

Desain responsif tidak berarti bahwa kebutuhan pengunjung seluler terpenuhi. Desain responsif masih perlu dioptimalkan untuk pengalaman pengguna. Dengan demikian, Google telah menyatakan bahwa desain responsif adalah opsi pilihan mereka untuk SEO seluler, tetapi telah mengonfirmasi tidak ada peningkatan peringkat yang didapat dari memiliki situs responsif. Skala gambar perlu diketahui tentang cara mengoptimalkan desain responsif untuk mobile SEO. Berikut ini adalah tampilan webite e-brosur dengan skala gambar yang responsif:

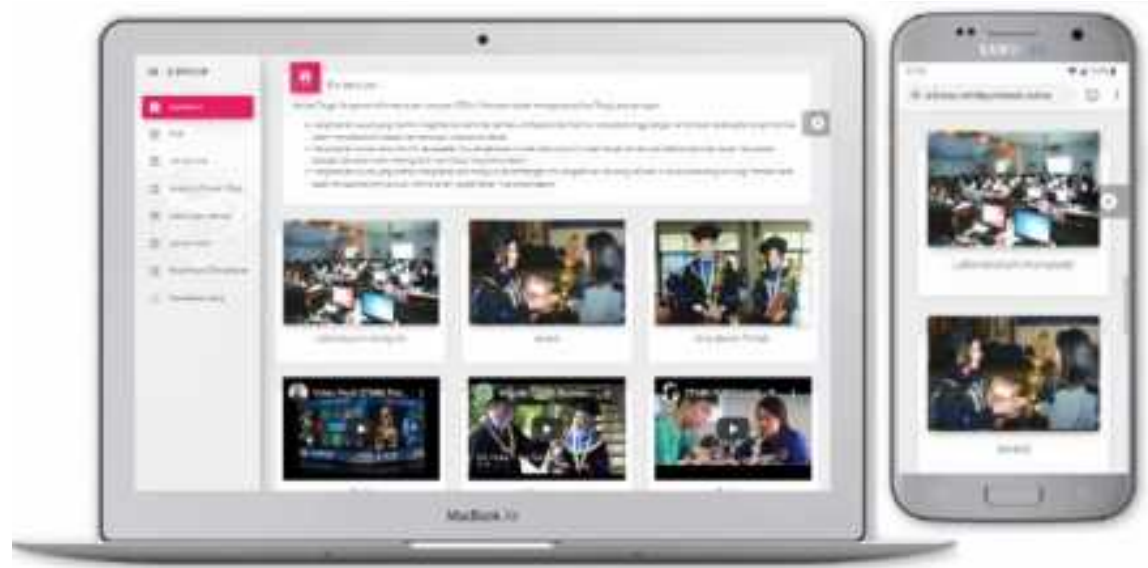

Gambar 4. Tampilan Webite E-Brosur Dengan Skala Gambar Responsif

Skala gambar yang digunakan adalah <meta content='width=device-width, initialscale $=1.0$, maximum-scale $=1.0$, user-scalable $=0$, shrink-to-fit $=$ no' name='viewport' $\mid>$. Membuat menu navigasi yang dapat diklik dan mudah dilihat sangat penting bagi pengguna seluler. Memperhatikan perilaku pengguna seluler sangat penting sebagai upaya untuk memahami apa yang pengguna cari di situs.

5) Optimizing an Adaptive Website for Mobile Search

Situs adaptif (atau RESS / disajikan secara dinamis) menggunakan URL yang sama, tetapi server mengirimkan versi HTML (dan CSS) yang berbeda berdasarkan jenis perangkat yang meminta halaman tersebut. Desain web adaptif seperti memiliki dua situs web yang sangat berbeda, dimana yang satu dirancang agar muat di ponsel sementara yang lainnya dirancang agar pas di desktop. Berikut ini adalah tampilan website e-brosur yang adaptive: 


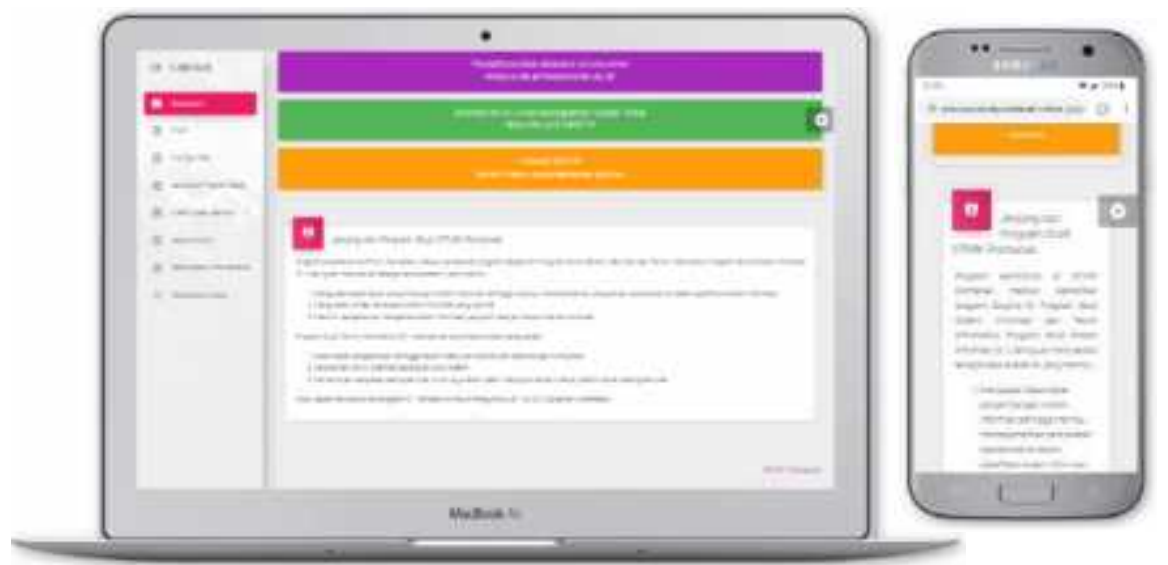

Gambar 5. Tampilan Website E-Brosur Adaptive

\section{PENGUJIAN SISTEM}

Pengujian sistem ini hanya melihat dari sisi bagaimana kualitas dari penerapan Meta Tag dan Mobile Friendly pada website e-brosur. Pengujian bertujuan untuk memastikan penggunaan Meta Tag dan Mobile Friendly sudah optimal apa belum. Dalam penelitian berusaha untuk mencapai tingkat optimal yang baik agar website e-brosur memberikan nilai tambah bagi STMIK Pontianak sebagai alat untuk menyebarkan informasi kepada masyarakat.

a. Pengujian Optimasi Meta Tag

Meta tags analyzer checker atau check meta tags dalam suatu website yaitu merupakan salah satu cara untuk mengecek membantu mengoptimalkan atau optimasi SEO on page dengan cara menganalisa metadata atau meta info dari suatu halaman website, di antaranya dari mulai judul, deskripsi, keywords atau kata kunci, mengukur persentase SEO score keywords yang relevan dengan konten atau artikel pada site tersebut, total heading tag dari H1 hingga H6, total kata kunci atau keywords dalam sebuah konten pada halaman website, serta keywords density yang mengukur persentase berapa jumlah total kata kunci atau keywords, total links page atau total tautan page termasuk total internal links, dan eksternal links pada halaman / page baik itu yang dofollow dan nofollow dari website tersebut. Berikut ini adalah hasil pengujian meta tag terhadap website e-brosur (http://e-brosur.stmikpontianak.online/):

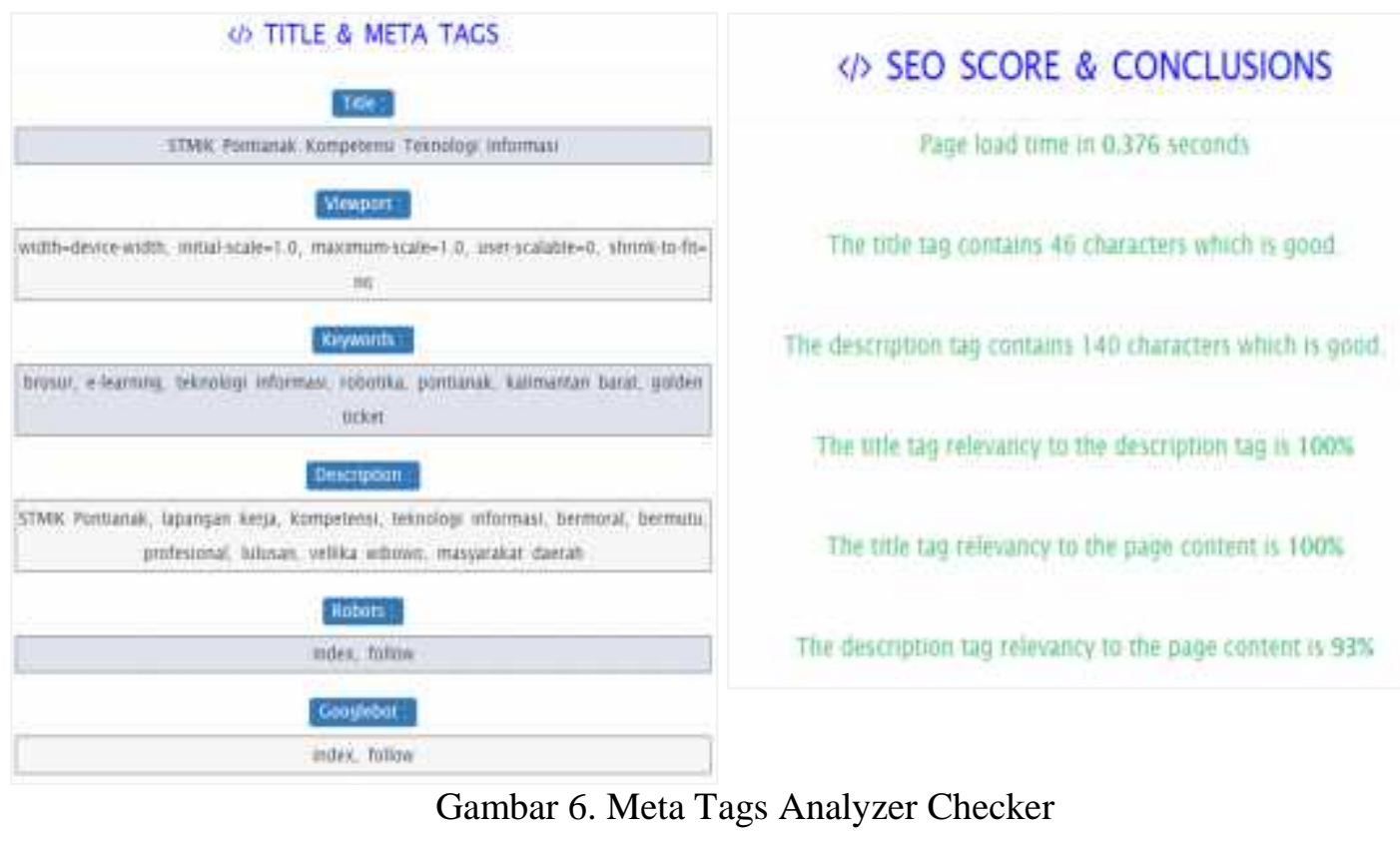


Semua meta tag ditampilan seperti title, viewport, keywords, description, robots, dan googlebot. Gambar berikutnya menampilkan informasi loading time yaitu 0.376 seconds. Kecepatan ini sudah sangat bagus dimana idealnya kecepatan web berkisar 2 hingga 5 detik. Jumlah karakter pada title adalah 46 dan dinyatakan bagus. Jumlah karakter pada description adalah 140 dan dinyatakan bagus. Selanjutnya title tag memiliki relevansi $100 \%$ dengan description tag, title tag memiliki relevansi $100 \%$ dengan page content dan description tag memiliki relevansi $93 \%$ terhadap page content.

\section{b. Pengujian Optimasi Mobile-Friendly}

Setiap situs web yang ramah terhadap perangkat mobile dapat dikatakan Mobile-friendly. Untuk menguji apakah situs e-brosur mendukung mobile-friendly, maka dapat menggunakan layanan dari Google webmasters tools. Hasil pengujian mencakup tangkapan layar tentang bagaimana laman tersebut terlihat oleh Google di perangkat seluler, serta daftar masalah kegunaan seluler apa pun yang ditemukannya. Masalah kegunaan seluler adalah masalah yang dapat memengaruhi pengguna yang mengunjungi halaman di perangkat seluler termasuk ukuran font kecil dan penggunaan Flash yang tidak didukung oleh sebagian besar perangkat seluler. Berikut ini adalah tampilan hasil pengujian Optimasi Mobile-Friendly pada website e-brosur:

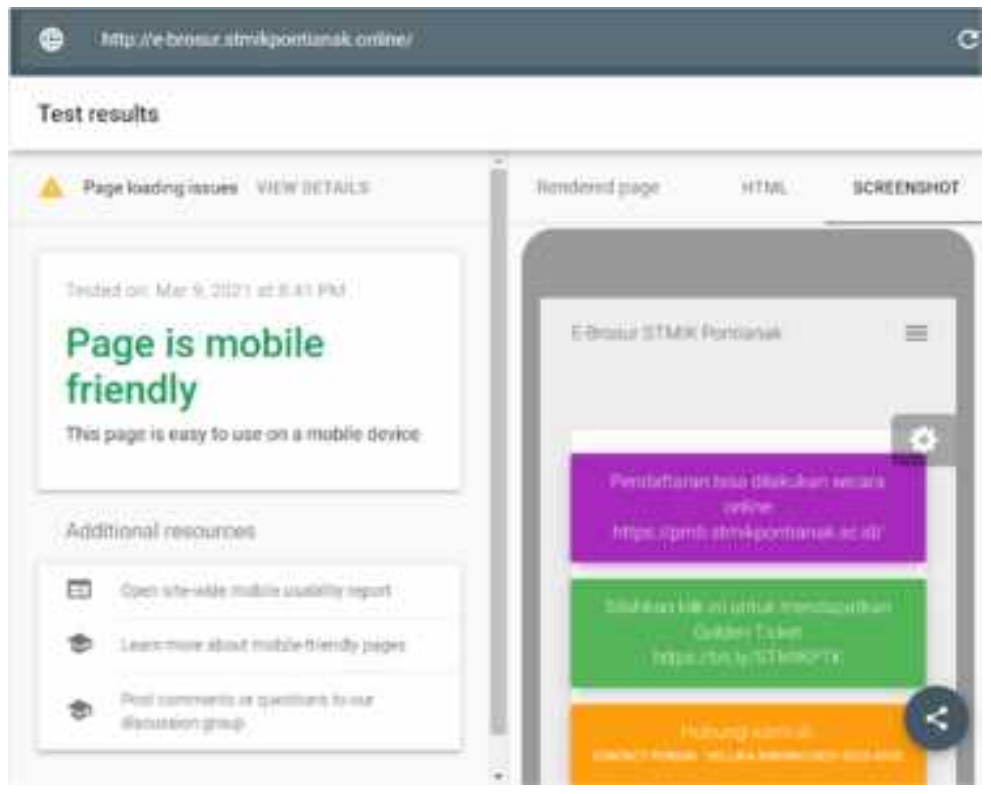

Gambar 7. Tampilan Optimasi Mobile-Friendly Pada Website E-Brosur

Dari gambar di atas dapat dijelaskan bahwa website e-brosur sudah masuk kategori mobile friendly. Hal ini dibuktikan oleh hasil test "page is mobile friendly" and "this page is easy to use on a mobile device".

\section{KESIMPULAN}

Penelitian melihat bahwa sangat penting untuk memaksimalkan agar konten yang terkandung dalam website e-brosur dapat dibaca oleh pengguna. Website yang menyediakan ebrosur atau sejenisnya sudah pasti sangat banyak sehingga dapat menghilangkan kemungkinan website e-brosur STMIK Pontianak dapat dibaca oleh masyarat. Search engine memiliki algoritma yang sangat rahasia dan selalu berubah dari waktu ke waktu. Kondisi ini menjadi tantangan bagi pengembang sistem untuk bagaimana menghadirkan website yang kontennya bisa dikenal oleh search engine dan bahkan dapat muncul diposisi paling atas. Penelitian ini bertujuan untuk menghasilkan SEO pada website e-brosur dengan cara mengoptimalkan penggunaan Meta Tag dan Mobile Friendly. Website e-brosur dikembang dengan pendekatan 
user experience (UX) dalam merancang user interface (UI) mengingat keterbatasan layar dalam menampilkan informasi dan kemudahan dalam melakukan navigasi. Hasil penelitian memberikan bukti bahwa mengoptimalkan Meta Tag sangat penting sebagai upaya untuk mencapai peringkat dalam pencarian google. Menghasilkan web yang mobile friendly juga menjadi hal yang sangat penting mengingat salah satu teknik pencarian google adalah memperhatikan website yang sifatnya responsif pada perangkat mobile. Keterbatasan penelitian ini terletak pada alat pengujian yang meta tag maupun pengujian mobile friendly sehingga belum bisa dikatakan bahwa website e-brosur akan berada diposisi paling atas ketika pencarian menggunakan google. Masih perlu dikembangkan dengan menggunakan algoritma search engine google terupdate.

\section{SARAN}

Sebagai upaya untuk menghasilan website e-brosur yang mampu dikenali oleh search engine dan bisa berada pada posisi atas, maka pengembang sistem harus memahami dengan baik algoritma yang dipergunakan oleh google dalam melakukan pelacakan terhadap kata kunci yang dipergunakan. Menghadirkan website yang mobile friendly juga harus mencari perioritas mengingat salah satu acuan bagi google dalam melakukan pencarian adalah melihat responsif dari suatu website dan bisa berjalan baik pada perangkat mobile. Menggunakan teknik pengujian meta tag dan mobile friendly harus diutamakan.

\section{UCAPAN TERIMA KASIH}

Penulis mengucapkan terima kasih kepada Sekolah Tinggi Manajemen Informatika dan Komputer (STMIK) Pontianak yang telah memberikan dukungan finansial terhadap penelitian ini. Terima kasih kepada rekan-rekan dosen yang telah memberikan masukan dan dukungan dalam menyelesaikan tulisan ini. Kepada para reviewer saya juga mengucapkan banyak terima kasih atas bimbingan dan arahannya sehingga tulisan ini dapat sesuai seperti apa yang diharapkan. Semoga tulisan ini dapat memberikan manfaat bagi banyak orang, saat ini maupun yang akan datang.

\section{DAFTAR PUSTAKA}

[1] Artanto, H., \& Nurdiyansyah, F. (2017). Penerapan SEO (Search Engine Optimization) untuk meningkatkan penjualan produk. JOINTECS (Journal of Information Technology and Computer Science), 2(1).

[2] Handayani, T., \& Pratama, G. F. (2020). Information Technology for Food Product. International Journal of Education, Information Technology, and Others, 3(2), 315-319.

[3] Anugerah, S. (2015, July). Pemodelan Responsive Web Menggunakan Foundation Framework Dalam Pengembangan Perangkat Lunak Berbasis Perangkat Bergerak. In Seminar Nasional Informatika (SEMNASIF) (Vol. 1, No. 1).

[4] Supiandi, I. (2016). Membangun SEO pada Web Sesuai Prinsip Dasarnya. INFOTECH journal, 2(1).

[5] Saputra, A., \& Astuti, Y. (2018). Analisis Pengaruh Struktur HTML Terhadap Rangking Search Engine Result Page. Jurnal Mantik Penusa, 2(2).

[6] Margea, R., \& Margea, C. (2017). Considerations for the Mobile Web. Paradigm Shift. Informatica Economica, 21(1). 
[7] Saputra, D. D., \& Ilhamsyah, D. P. IMPLEMENTASI FRAMEWORK ACCELERATED MOBILE PAGES PADA PENGEMBANGAN WEBSITE PROGRAM STUDI SISTEM INFORMASI. Coding Jurnal Komputer dan Aplikasi, 8(2).

[8] Himawan, H., Arisantoso, A., \& Saefullah, A. (2017). Search Engine Optimization (SEO) Menggunakan Metode White Hat SEO Untuk Meningkatkan Peringkat dan Trafik Kunjungan Website. Prosiding SNATIF, 783-790.

[9] Triyanto, W. A. (2017). Optimasi meta tag HTML untuk meningkatkan Search Engine Optimization (SEO) pada website e-commerce UMKM. IJNS-Indonesian Journal on Networking and Security, 6(4).

[10] Pratama, R. P., Faisal, M., \& Hanani, A. (2019). Deteksi Plagiarisme pada Dokumen Jurnal Menggunakan Metode Cosine Similarity. SMARTICS Journal, 5(1), 22-26.

[11] Hayaty, M., \& Meylasari, D. (2018). Implementasi Website Berbasis Search Engine Optimization (SEO) Sebagai Media Promosi. Jurnal Informatika, 5(2), 295-300.

[12] Handayani, I., Febriyanto, E., \& Shofwatullah, M. (2019). Optimalisasi visibilitas situs iLearning Journal Center (iJC) Pada Mesin Pencari Berbasis Search Engine Optimization (SEO) On Page. Sains dan Teknologi Informasi, 5(1), 27-35.

[13] Bahri, S. (2020). IMPLEMENTASI TEKNIK SEO (SEARCH ENGINE OPTIMIZATION) PADA ARTIKEL UNTUK MENEMPATI HALAMAN 1 PENCARIAN GOOGLE. Jurnal Sintaksis, 3(1), 41-48.

[14] Purwiantono, F. E. (2019). Metode Search Engine Optimization (SEO) Untuk Meningkatkan Ranking Webometrics Pada Web STIKI Malang. INFORMATION SYSTEM FOR EDUCATORS AND PROFESSIONALS: Journal of Information System, 3(2), 111-120.

[15] Saptari, J., Iswandari, R., \& Setyawati, R. (2018). User Experience (UX) dalam pemanfaatan fasilitas Informal Learning Space (ILS) perpustakaan. Berkala Ilmu Perpustakaan dan Informasi, 14(1), 26-34.

[16] Priyatna, B. 2019, Penerapan Metode User Centered Design (UCD) Pada Sistem Pemesanan Menu Kuliner Nusantara Berbasis Mobile Android, Jurnal Accounting Information System (AIMS), vol. 2, no. 1, hal. 17-30.

[17] Santi, R. C. N. 2016, Perancangan Interaksi Pengguna (User Interaction Design) Menggunakan Metode Prototyping, JURNAL TEKNIK INFORMATIKA, vol. 9, no. 2, hal. 108-113.

[18] Sari, R., Utami, E., \& Amborowati, A. 2015, Rancangan Lowongan Kerja Online Menggunakan Metode User Centered Design (Studi Kasus: Business Placement Center STMIK AMIKOM Yogyakarta), Creative Information Technology Journal, vol. 3, no. 1, hal. 62-73. 